\title{
HYPERTENSION AND DEPRESSION
}

\author{
Andréia Zavaloni Scalcoํ, Mônica Zavaloni Scalco² ${ }^{2}$, João Batista Serro Azul ${ }^{3}$, and \\ Francisco Lotufo Neto ${ }^{1}$
}

Scalco AZ, Scalco MZ, Azul JBS, Lotufo Neto F. Hypertension and depression. Clinics. 2005;60(3):241-50.

Despite the high prevalence of depression and hypertension, the relationship between the two diseases has received little attention. This paper reviews the epidemiological, pathophysiological, and prognostic aspects of this association, as well as its implications for treatment. A Medline search was conducted using the following key words: depression, blood pressure, blood pressure variability, physical morbidity, hypertension, mood, stress, hypertension, antidepressive agents, and genetics, from 1980 to 2004. We found descriptions of increased prevalence of hypertension in depressed patients, increased prevalence of depression in hypertensive patients, association between depressive symptomatology and hypotension, and alteration of the circadian variation of blood pressure in depressed patients. There is considerable evidence suggesting that hyperreactivity of the sympathetic nervous system and genetic influences are the underlying mechanisms in the relationship between depression and hypertension. Depression can negatively affect the course of hypertensive illness. Additionally, the use of antidepressive agents can interfere with blood pressure control of patients with hypertension by inducing changes in blood pressure and orthostatic hypotension.

KEYWORDS: Depression. Cardiology. Hypertension. Blood pressure. Antidepressive agents.

Several studies have focused on the association between depression and cardiovascular diseases; however, the relationship between depression and hypertension has received less attention. Nevertheless, interactions between blood pressure (BP) and psychic factors have been observed. O'Hare observed that by asking hypertensive patients to talk about health problems or other life stresses, he could induce substantial increases in their BP, and while after resting quietly for 20 to $40 \mathrm{~min}$ utes, they had large drops in BP. ${ }^{1}$ Over the next several decades, these observations were replicated many times by other investigators who also found that BP measurements by a doctor are frequently accompanied by marked increased BP and heart rate (HR). This increase (named the "white-coat" effect) is quite common and is believed to be a consequence of an

Psychiatry Institute ${ }^{1}$, Hospital das Clínicas, Faculty of Medicine, University of São Paulo - São Paulo/SP, Brazil.

Department of Psychiatry ${ }^{2}$, University of Toronto - Toronto/Ontario, Canada.

Heart Institute $^{3}$, Hospital das Clínicas, Faculty of Medicine, University of São Paulo - São Paulo/SP, Brazil.

E-mail: ascalco@usp.br

Received for publication on June 03, 2004.

Accepted for publication on February 10, 2005. anxiety response to the doctor's visit. ${ }^{2}$

Since both hypertension and depression are highly prevalent, it is extremely important to better understand the relationship between them.

\section{METHOD}

This paper reviews the epidemiological, pathophysiological, and prognostic aspects of the association between hypertension and depression, as well as its implications for treatment. The method was a Medline search, which was conducted using the following key words: depression, blood pressure (BP), blood pressure variability (BPV), physical morbidity, hypertension, mood, stress, hypertension, antidepressive agents, and genetics, from 1980 to 2004 .

\section{RESULTS}

\section{Epidemiologics aspects}

Both hypertension and hypotension have been observed in association with depression or depressive symptoms. 


\section{Hypertension in depressive patients}

An increased prevalence of hypertension in depressed patients has been described by Adamis and Ball. ${ }^{3}$ They studied the comorbidity between psychiatric and physical diseases in 75 elderly psychiatric inpatients, and found that depressed patients had more cardiovascular diseases and hypertension than other psychiatric patients. ${ }^{3}$ Nakagawara et $\mathrm{al}^{4}$ also found an increased frequency of hypertension in depressed patients, but only in those with melancholic features.

A depressive mood has also been associated with higher BP levels, ${ }^{5,6}$ being positively associated with higher levels of systolic BP (SBP) and diastolic BP (DBP) in 24-hour BP monitoring of 54 subjects over 7 days. ${ }^{5}$ Additionally, significantly higher BP was found in 15 subjects with a clinical diagnosis of depression. ${ }^{5}$

Prospective studies have also suggested that depression may be a risk factor for the development of hypertension. In a study of 2992 normotensive subjects (25 to 64 years) who were followed for 6 to 7 years, to evaluate the prospective association between depressive symptoms and development of hypertension, high scores of depressive symptoms doubled the risk for hypertension, defined as a BP of $160 / 95 \mathrm{~mm} \mathrm{Hg}$ or over, or a prescription of antihypertensive medications. ${ }^{7}$

Symptoms of depression and anxiety, measured by the General Well-Being Schedule were also associated with elevated risk of incident hypertension $(n=3310)$, and this effect was more pronounced in black women $(\mathrm{RR}=3.12 ; 95 \%$ $\mathrm{CI}=1.24-7.88)$ compared to white women $(\mathrm{RR}=1.73 ; 95 \%$ $\mathrm{CI}=1.30-2.30)$ or men $(\mathrm{RR}=1.56 ; 95 \% \mathrm{CI}=1.08-2.25){ }^{8}$

\section{Depression in hypertensive patients}

Increased prevalence of depression has been described in hypertensive patients as well. Rabkin et al. found a 3fold higher frequency of major depression in patients treated for hypertension. ${ }^{9}$

Hopelessness was associated with increased incidence of hypertension in 616 initially normotensive men, in a 4year follow-up prospective study in Finland. Men reporting high levels of hopelessness at baseline were 3 times more likely to become hypertensive than men who were not hopeless, after adjustments for age, body mass index, baseline resting $\mathrm{BP}$, physical activity, smoking, alcohol consumption, education, and parental history of hypertension. ${ }^{10}$

\section{Hypotension and Depression}

Conversely, the concept of a "hypotensive syndrome" emerged in the 1980s. It consisted of somatic symptoms such as tiredness, dizziness, headaches, with occasional minor psychiatric symptoms such as anxiety and depression. ${ }^{11}$
Numerous treatments were tried, ranging from harmless tonics to digoxin, amphetamine, and ergotamine. Other associated symptoms included general fatigue, overexertion, psychosomatic symptoms, readiness to cry, feeling scared and panicky, feeling under strain, unable to enjoy normal activities, and unable to concentrate. ${ }^{11-14}$ Several authors suggested that a primary psychiatric disorder such as depression could account for the symptoms of the syndrome and could be related to low BP as well.

There are also recent descriptions of low BP associated with depressive symptoms. In a study of 2723 elderly persons living in the community, hypotension was associated with increased depressive symptomatology, after adjustments for age, gender, and prescriptions for antihypertensives. Hypotensive subjects also had lower self-esteem. $^{15}$

An inverse relationship between low diastolic BP (DBP) and depressive symptoms was demonstrated in a populational study with 846 elderly men without a psychiatric diagnosis. Higher levels of depressive symptoms and more diagnosis of depression were found in those subjects with DBP $<75 \mathrm{~mm} \mathrm{Hg}$. Men with diastolic hypertension had more affective and somatic symptoms, such as fatigue, pessimism, sadness, and loss of appetite, weight loss, and preoccupation with health. ${ }^{16}$

\section{Abnormal Circadian Blood Pressure Regulation}

Abnormal circadian BP regulation has been associated with depression. ${ }^{17}$ Depressive symptoms were associated with a higher night/day systolic BP (SBP) ratio in 126 men who were without psychiatric diseases and medicationfree. ${ }^{17}$ Autonomic nervous system dysfunction and abnormal hormonal regulation have been hypothesized to explain the results. ${ }^{17}$

In another study, self-reported depression was associated with higher SBP and DBP measurements and lower day/ night BP ratios. ${ }^{18}$

Nevertheless, $24 \mathrm{~h}$ blood pressure monitoring revealed an increased mean $24 \mathrm{~h}$ SBP but normal nighttime BP level in a substantial subgroup of depressed inpatients, resulting in a high day/night BP ratio. The subjects had no hypertension but presented more cardiovascular reactivity during the day and difficulty in falling asleep in the evening. ${ }^{19}$ Additionally, less effective BP regulation in response to an orthostatic challenge has been associated with depression in 33 subjects. ${ }^{20}$

Another indicator of poor BP regulation in depressive patients was the larger postprandial drop in systolic BP detected by Schwartz et al. ${ }^{21}$

There are also studies that failed to find an association between depression and BP. No significant differences in 
BP were found between depressed and nondepressed psychiatric inpatients $(\mathrm{n}=1046){ }^{22}$ The CARDIA Study (1996) examined cross-sectional relationships among depressive symptoms, anxiety, alcohol intake, and blood pressure in a sample of 4352 adults and found that depressive symptoms and anxiety were unrelated to $\mathrm{BP}{ }^{23}$

\section{Pathophysiology}

\section{Depression and Autonomic Nervous System (ANS)}

The physiological mechanisms underlying the relationship between depression or anxiety and BP probably involve the effect of the sympathetic nervous system. ${ }^{23,24}$

Data available at present show that sympathetic activation is a specific feature of essential hypertension, and it may play a pathogenic role in this disease. A metanalysis showed that plasma noradrenaline, as an indirect marker of sympathetic tone, was elevated in patients with essential hypertension. ${ }^{25}$ In addition, it was shown that the rate of noradrenaline spillover from sympathetic nerve terminals was sometimes increased in essential hypertension. ${ }^{26}$ Additional data have emerged from direct measurements of sympathetic nerve traffic to skeletal muscle circulation using a microelectrode technique (microneurography). Most studies using this method have demonstrated increased sympathetic nerve activity in patients with essential hypertension. In contrast, patients with secondary hypertension did not differ from normotensive patients. ${ }^{26}$

There is also reported evidence showing abnormal autonomic nervous system function in depression, specifically regarding increased sympathetic activity and poor vagal control. Several studies have examined cerebrospinal fluid (CSF), plasma or urinary levels of norepinephrine (NE) and its major central nervous system metabolite, 3-methoxy-4hydroxyphenylglycol (MHPG). Plasma NE and/or MHPG levels have been reported to be elevated in depressive patients. ${ }^{27-30}$ Norepinephrine was significantly elevated in depressive patients compared with controls, although the rate of NE clearance from plasma was similar in both groups. ${ }^{31}$ Maes et al. measured the $24 \mathrm{~h}$ urinary excretion of noradrenaline (NA), adrenaline (A), dopamine (DA), and MHPG in depressed subjects. There were significant positive correlations between sleep disorders and NA, A, and DA excretion. The excretion of MHPG was negatively related to anxiety and hypochondriasis. It was suggested that these relationships between these symptoms and the dysfunction in the turnover of catecholamines could reflect the occurrence of a hyperarousal state in some major depressive disorders. ${ }^{32}$

Other indicators of sympathetic nervous activity have also been studied in depressive patients. Lechin et al. found higher heart rate increases during orthostasis and exercise periods and greater NA values in depressed patients, suggesting maximal neural sympathetic activity in them. ${ }^{33}$ Bruno et al. assessed cardiovascular autonomic functioning in 22 unipolar depressive inpatients. Sympathetic cholinergic, alpha- and beta-adrenergic activity was assessed via the measurement of forearm blood flow (FBF) and the cardiac pre-ejection period (PEP). Significant negative correlations were found between depressive symptoms and FBF and significant positive correlations were found between depressive symptoms and PEP. It was concluded that the autonomic profile of depression is characterized by a decrease in central sympathetic cholinergic outflow, coupled with increases in alpha-adrenergic and in beta-adrenergic activity. ${ }^{34}$ Diminished heart rate variability (HRV) also reflects increased sympathetic activity and decreased parasympathetic activity in depressive patients. ${ }^{35-40}$ Twentyfour hour ECG recordings were obtained from major depressive patients, normal controls, and medically healthy volunteer participants. High-frequency variability was markedly diminished in depressed patients, indicating that they may have an abnormality in parasympathetic nervous system activity. ${ }^{41}$ In another study, 380 acute myocardial infarction (MI) patients with depression and 424 acute MI patients without depression were compared. All but one HRV index remained significantly lower in patients with depression than in patients without depression, suggesting increased sympathetic activity and/or decreased parasympathetic modulation. ${ }^{37}$ Increases in HRV were positively correlated with post-treatment Hamilton Rating Scale for Depression (HAM-D) scores after a therapeutic trial of various antidepressant medications. ${ }^{42,43}$ On the other hand, patients treated with mirtazapine or amytriptiline showed significant decreases in HRV after the treatment. ${ }^{44}$

The hypothesis of hyperactivity of the sympathetic nervous system is not the only possible explanation for the relationship between depression and BP. Siever and Davis ${ }^{45}$ proposed that the activity of neurotransmitter systems in affective disorders may be better understood as a reflection of a relative failure in their regulation, rather than simple increases or decreases in their activity. Thus, the impairment in the regulation of the noradrenergic system would be expected to disturb the individual affective responsiveness to external or internal stimuli. Stressful stimuli that episodically increase noradrenergic activity would be associated with dysphoric hyperarousal because this arousal would not be easily dampened by feedback mechanisms. Decreases in noradrenergic availability secondary to depletion by periodic excessive release could easily be seen as mediating anergic and vegetative symptoms. The exact configuration of these abnormalities might vary depending on the indi- 
vidual and/or phase of the illness, so that appetite, sleep, and motor activity may be decreased or increased in depression. ${ }^{45}$ Siever and Davis' theory seems very interesting and could explain the increased vulnerability for hypertension in depression. In addition, this theory is in accordance with the mixed BP findings in depressive patients.

Sloan et al. also associated autonomic control and BP to depression. Established psychological/behavioral risk factors for coronary artery disease (CAD), such as depression, hostility, and anxiety, are associated with diminished control of the heart, which may disinhibit pathogenic BP variability (BPV). ${ }^{46}$ Blood pressure oscillates at high (0.15$0.5 \mathrm{~Hz})$ and lower frequencies $(0.02-0.15 \mathrm{~Hz})$. An intact autonomically mediated cardiac control system, including baroreflexes, acts to buffer fluctuations in BP, especially in response to challenge. This increased BPV is harmful to the coronary arteries, contributing to plaque formation, plaque rupture, and acute coronary events. It is also related to greater left ventricular mass, higher urinary albumin excretion, carotid atherosclerosis, and cardiovascular morbidity in hypertensive subjects. ${ }^{46}$ In CAD patients, depression was associated with low baroreflex sensitivity. ${ }^{47}$

\section{Stress and ANS}

There is a considerable amount of data linking sympathetic nervous system hyperresponsivity to the development of hypertension. Hyperresponsivity is manifested by exaggerated HR and BP responses to psychological stimuli, experienced as engaging, challenging, or aversive. ${ }^{48}$ One line of evidence suggesting a link between hyperreactivity and hypertension is the similarity between autonomically-mediated cardiovascular changes in the presence of borderline hypertension and those evoked in more reactive normotensive persons during certain types of behavioral events. Studies of hemodynamics in borderline hypertensive patients have shown an increased cardiac output, mediated by enhanced beta-adrenergic activity and decreased parasympathetic stimulation of the heart. ${ }^{1}$

Patients with established hypertension have been observed to show greater HR and BP increases than normotensive subjects in response to behavioral events such as difficult mental arithmetical operations, or interpersonal interactions designed to arouse fear or anger or to expose personal conflicts. ${ }^{1}$

Hyperreactivity seems to be related to psychosocial aspects. Elevation of BP was associated with certain personality traits, such as anger and its suppression, and also to unexpected unfortunate life events. ${ }^{49,50}$ Evidence about the relationship between these factors and hypertension also points to an autonomic nervous dysfunction. ${ }^{1,49}$

Compared with nonhostile individuals, hostile subjects manifest higher HR and BP responses to physiological stimuli, such as mental tasks, as well as higher ambulatory BP levels during daily-life activity., Evidence also suggests that hostile individuals are more likely to exhibit hypercortisolemia and high levels of circulating catecholamines, as well as diminished beta-adrenergic receptor function of mononuclear leukocytes, diminished vagal modulation of heart function, and increased platelet reactivity. ${ }^{48}$

The "white-coat effect" was addressed by Grassi et al. by quantifying the sympathetic outflow to muscle and skin by microneurography. Measurements were performed in hypertensive subjects during a control period, during a visit by a doctor unfamiliar to the patient, and during a recovery period. The doctor's visit induced a sudden, marked, and prolonged BP and HR response, accompanied by a significant increase in skin and sympathetic nerve traffic, characterized by activation of the adrenergic nervous system. ${ }^{51}$

Interestingly, borderline hypertensive subjects with BP hyperreactivity also had higher negative affect scores after tasks, suggesting an association between depressive symptoms and hyperreactivity. ${ }^{52}$

Studies have demonstrated that relaxation training and biofeedback can lead to significant in-clinic BP reductions. It is suggested that individuals reporting high levels of anxiety should be considered initially for relaxation training. ${ }^{53}$ The BP lowering effects attributable to relaxation and biofeedback training were carried over to the working day. ${ }^{54}$ Initial evidence suggests that the long-term effects of practice of these procedures are consistent with the decreased responsitivity to plasma norepinephrine. ${ }^{53} \mathrm{~A}$ follow-up study demonstrated that the advantage for relaxation training was maintained 15 months after treatment. ${ }^{53}$ Nevertheless, the specific physiologic and neurohormonal mechanisms by which these effects are obtained are not known. ${ }^{53}$

\section{Genetic Vulnerability}

It is also widely accepted that BP and susceptibility to hypertension are influenced by genetic factors. ${ }^{55}$ Recently, twin, adoption, and family studies have suggested that genetic factors are important in the etiology of mood disorders. ${ }^{56}$ Some studies have suggested that a shared genetic vulnerability could explain the relationship between depression and hypertension.

Grewen et al. ${ }^{55}$ investigated whether parental history of hypertension $(\mathrm{FH}+)$ enhances the impact on ambulatory blood pressure (ABP) of depressed mood as indexed by the Beck Depression Inventory (BDI), $(n=314)$. Higher BDI scores were significantly associated with higher 24-hour $\mathrm{ABP}$ in $\mathrm{FH}+$ subjects, but not in participants without parental history of hypertension (FH-). Relationships were sig- 
nificantly stronger in those with 2 hypertensive parents vs. those with 1 vs. those with no hypertensive parents. In contrast, interaction was least predictive of BP levels during sleep, suggesting that the influence of depression on BP in FH- subjects is manifested during responses to everyday stresses and strains. ${ }^{55}$

Subjects with a positive family history of hypertension exhibited higher tonic levels of BP and HR at rest, during mental stress tasks, and during recovery. ${ }^{57}$ Individuals with positive family histories reported more depression during the tasks, suggesting that genetic and psychological factors are involved with cardiovascular hyperreactivity. ${ }^{57}$

Rats that were genetically prone to hypersensitivity had a very high propensity for developing depression (learned helpless behavior). Moreover, hyporesponsive functioning of the hypothalamus-pituitary-adrenal (HPA) axis correlates with a propensity for learned helpless behavior. ${ }^{58} \mathrm{In}$ terestingly, the blockade of the renin-angiotensin system with the angiotensin converting enzyme inhibitor reversed the learned helplessness in rodents. ${ }^{59}$ Additionally, several clinical investigations have suggested that captopril, an angiotensin-converting enzyme inhibitor exhibits antidepressant properties in humans, suggesting that the renin-angiotensin system may not only participate in the elevation of BP but may also contribute to depression, although its mechanism is unknown. ${ }^{58}$

However, there are controversial findings. Depressive symptoms measured by the CES-D (Centers for Epidemiological Studies-Depression Scale) were associated with mean arterial pressure (MAP) in 87 monozigotic twin pairs and 86 dizigotic twin pairs. ${ }^{60}$ Nevertheless, the association accounted for an environmental effect that was independent of genetic effects. ${ }^{60}$ Another study found no association between depression and genetic polymorphisms related to vascular disease. ${ }^{61}$

\section{Complications}

Although there is no definitive evidence of an association between depression and development of hypertension, depression can impair the management and prognosis of hypertension. ${ }^{62,63}$

An epidemiological study analyzed the longitudinal association between depressive symptomatology and BP control, stroke, and cardiovascular-related mortality in the elderly. This study demonstrated an increased risk of stroke among older patients with hypertension and high levels of depressive symptoms, and the association appeared to be a function of BP control, particularly in women. ${ }^{62}$

Depression has also been associated with higher risk of stroke in the elderly. In a prospective study, depressive symptoms were predictive of ischemic stroke in 901 subjects in a Japanese rural area during a 10 -year period. ${ }^{64}$ Wassertheil-Smoller et al. ${ }^{63}$ detected that a significant excess risk of death and stroke or myocardial infarction was associated with an increase in depressive symptoms in patients with 60 years of age or more $(n=4736)$ and with systolic hypertension ( $\mathrm{SH}$ ), defined as $\mathrm{SBP} \geq 160 \mathrm{~mm} \mathrm{Hg}$ and DBP $<90 \mathrm{~mm} \mathrm{Hg}$.

Depression was independently associated with a substantial increase in the risk of heart failure among 4538 persons aged 60 years and older with isolated systolic hypertension in a study for which the average follow-up period was 4.5 years $(\mathrm{RR}=2.59 ; 95 \%$ CI: $1.57-4.27) .{ }^{65}$ Depressed persons also had higher SBP levels. ${ }^{65}$

Depression independently increased the risk of mortality in the 4-year follow-up period of 2847 subjects with 55 to 85 years old. ${ }^{66}$ The relative risk for mortality was 1.6 (95\% CI: 1.0-2.7) in subjects with minor depression and cardiac disease, 1.5 (95\% CI: 0.9-2.6) in subjects with minor depression without cardiac disease, 3.0 (95\% CI: 1.1-7.8) in subjects with major depression and cardiac disease and 3.9 (95\% CI: 1.4-10.9) in subjects with major depression without cardiac disease. A dose-response effect was demonstrated in that the more severe the depression, the higher the mortality risk. ${ }^{66}$

Heightened susceptibility to platelet activation may be a mechanism underlying the increased risk of ischemic heart and cerebrovascular disease and/or mortality after MI in depression. ${ }^{67}$ Hypertensive patients with higher scores on standardized depression rating scales showed significantly greater platelet reactivity following serotonin stimulation compared to patients with lower depression scores. ${ }^{68}$

On the other hand, hypertension has been proposed as a risk factor for the development of depression. Neuroimaging studies reveal higher frequency of ischemic abnormalities in late-life depression. ${ }^{69}$ According to the theory of vascular depression, these abnormalities could represent a vulnerability to depression. ${ }^{3}$

\section{Antidepressive treatment}

Another implication of the presence of depression in hypertensive patients is represented by the side effects of antidepressive agents. Tryciclic antidepressants (TCAs) and monoamine oxidase inhibitors (MAOI's) have been associated with both reduction and elevation in systolic and diastolic BP. ${ }^{12}$ Although serotonin selective reuptake inhibitors (SSRIs) produce fewer hemodynamic effects, hypertension in patients taking SSRIs has also been reported. ${ }^{12}$ A metanalysis of BP changes in patients treated with venlafaxine, imipramine, or placebo demonstrated a dose- 
dependent increase in BP with venlafaxine treatment. ${ }^{70}$ Sustained hypertension (defined as a resting diastolic BP value $\geq 90 \mathrm{~mm} \mathrm{Hg}$ plus a $\geq 10 \mathrm{~mm} \mathrm{Hg}$ rise above baseline diastolic $\mathrm{BP}$ for at least 3 consecutive clinical visits) was observed in $4.8 \%$ of patients treated with venlafaxine, $4.7 \%$ of those treated with imipramine, and $2.1 \%$ of those receiving the placebo. The largest increases $(13.2 \%)$ occurred at doses $\geq 300 \mathrm{mg}$ daily. ${ }^{70}$ Interestingly, more than one third of the hypertensive patients also showed a spontaneous reduction in BP during continued venlafaxine treatment. Patients with a history of preexisting hypertension or pretreatment diastolic BP >90 mm $\mathrm{Hg}$ did not demonstrate a greater risk for developing drug-induced hypertension. ${ }^{70}$ Another metanalysis was performed using original BP data of 3744 patients with major depression studied in controlled clinical trials comparing venlafaxine, imipramine, and placebo. Venlafaxine and imipramine were associated with small, but statistically significant increases in supine diastolic BP. The effect of venlafaxine was dose-dependent as well and did not adversely affect the control of BP for patients with preexisting high BP. However, the BP elevations were persistent during continuation of therapy. ${ }^{71}$

Another study examined BP in 796 depressed patients taking fluoxetine $20 \mathrm{mg}$ daily for up to 12 weeks. A modest reduction in SBP and DBP measures was observed. Patients pretreated with DBP $<60 \mathrm{~mm} \mathrm{Hg}$ showed a modest increase in mean DBP. Patients with preexisting cardiovascular disease, including hypertension, showed no significant BP changes. ${ }^{12}$

Potentiation of noradrenergic neurotransmission may be a mechanism by which antidepressants increase BP. In hy- pertensive crises associated with MAOI therapy, high levels of unmetabolized tyramine or sympathomimetics trigger norepinephrine release from peripheral sympathetic neurons. ${ }^{71}$ A regional increase of cardiac noradrenergic activity may the mechanism by which desipramine (a potent norepinephrine reuptake inhibitor) increases $\mathrm{BP} .^{72}$

Another hypothesis is that central serotoninergic transmission may have an essential role in BP regulation. The serotonin reuptake blockade could initiate a cascade of changes in central serotonin neurotransmission that results in an enhancement of autonomic tone. ${ }^{12}$ Grubb et al. have consistently demonstrated that fluoxetine and sertraline can increase and stabilize low BP in patients with neurocardiogenic hypotension and also provide sustained prophylaxis against recurrent hypotension. ${ }^{73-76}$

In clinical terms, the risk of orthostatic hypotension $(\mathrm{OH})$ during the tricyclic pharmacotherapy is far more important than elevations of BP. The MAOIs also cause relatively high rates of $\mathrm{OH}^{71}$

The elderly are more vulnerable to $\mathrm{OH}$. Occurence of $\mathrm{OH}$ and its association with the complaint of dizziness was studied in depressive elderly women receiving nortriptyline 35 to $100 \mathrm{mg}$ daily for 8 weeks. ${ }^{77}$ Normotensive and hypertensive subjects (BP controlled with thiazide diuretics) were compared. BP and HR were assessed at baseline and at every 2 weeks, and a tilt-table test was performed before and after treatment. There was an increase in the SBP drop on orthostasis in both groups (the mean SBP drop was $10.5 \mathrm{~mm} \mathrm{Hg}$ for hypertensive and $7.7 \mathrm{~mm} \mathrm{Hg}$ for normotensive women) and an increase in HR (mean increase of $14 \mathrm{bpm}$ ) (Fig. 1). Orthostatic hypotension was observed in

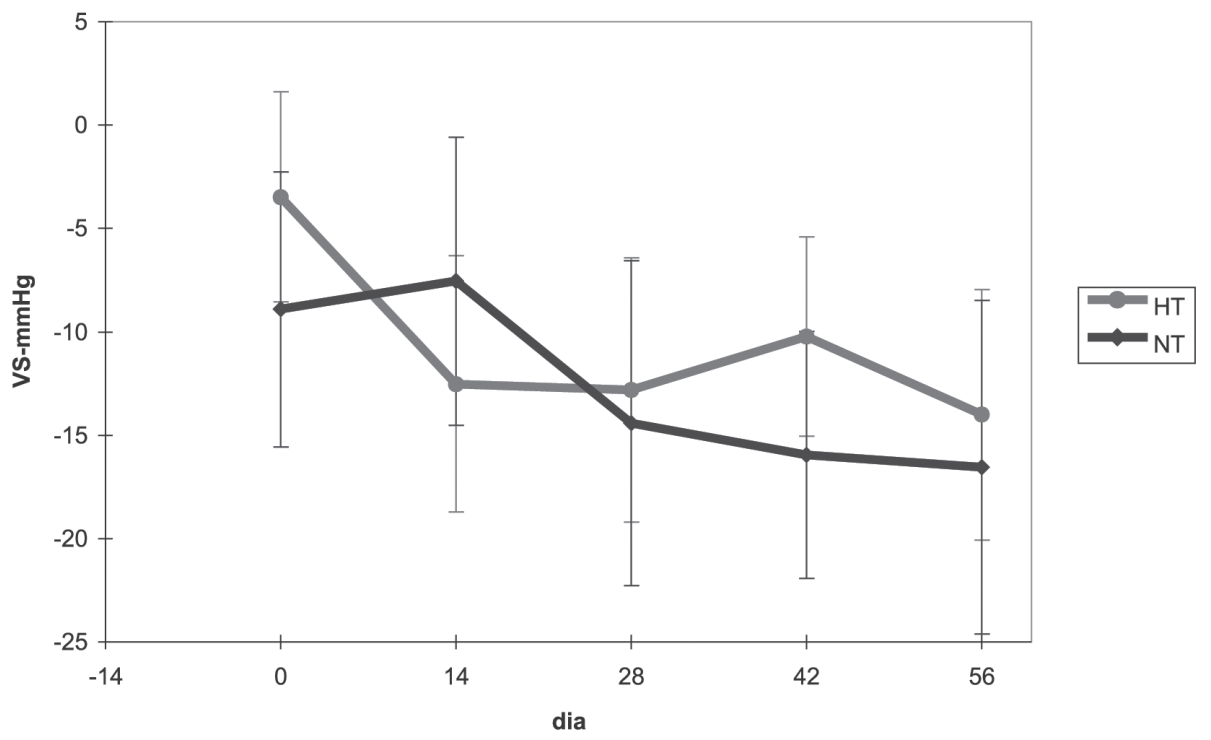

Figure 1 - Variation in systolic blood pressure at orthostasis (VS) during 8 weeks of treatment with nortriptyline. HT = hypertensive (21); NT = normotensive (22). Means and 95\% confidence intervals (vertical bars). (Modified with authorization from Scalco MZ, Almeida OP, Hachul DT, Castel S, Serro-Azul J, Wajngarten M. Comparison of risk of orthostatic hypotension in elderly depressed hypertensive women treated with nortriptyline and thiazides versus elderly depressed normotensive women treated with nortriptyline. Am J Cardiol. 2000;85:1156-58). 


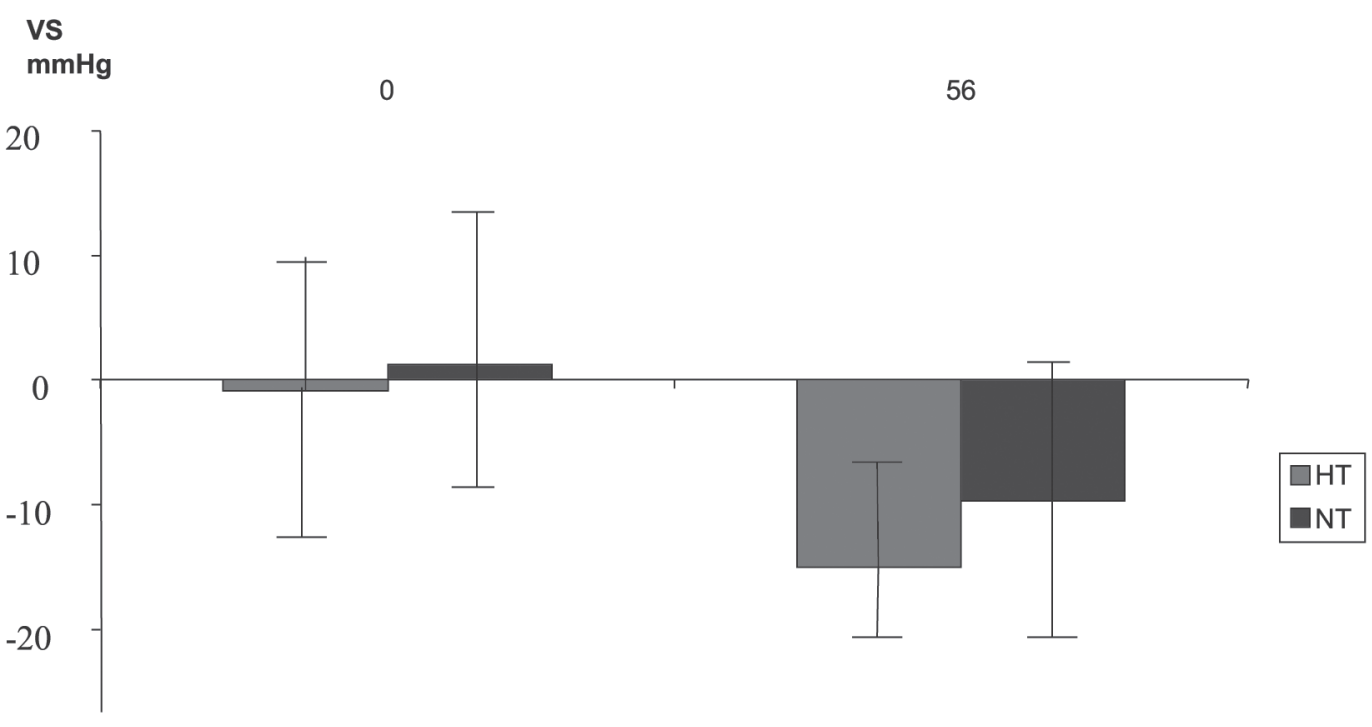

dia

Figure 2 - Variation in systolic blood pressure at orthostasis during the tilt-table test before and after treatment. HT = hypertensive $(19)$; NT = normotensive (21). Means and 95\% confidence intervals (vertical bars). (Modified with authorization from Scalco MZ, Almeida OP, Hachul DT, Castel S, Serro-Azul J, Wajngarten M. Comparison of risk of orthostatic hypotension in elderly depressed hypertensive women treated with nortriptyline and thiazides versus elderly depressed normotensive women treated with nortriptyline. Am J Cardiol. 2000;85:1156-58).

$21 \%$ of patients at baseline and in $33 \%$ after 8 weeks treatment. Results of tilt-table tests confirmed this increase in the frequency of $\mathrm{OH}$ after treatment (Fig. 2). There was no correlation between $\mathrm{OH}$ and subjective complaints of dizziness before or after treatment. Dizziness was reported by $53 \%$ and $38 \%$ of patients before after treatment, respectively, suggesting that depression was probably involved with the frequency of complaints of dizziness. ${ }^{77}$

Depressive patients have been considered to have a higher risk of $\mathrm{OH}$ while receiving tricyclic antidepressants compared to controls. ${ }^{78}$ Autonomic dysfunction associated with depression could contribute to the vulnerability. Additionally, higher postprandial SBP drops have been described in the subsyndromal depressed elderly. ${ }^{79}$

A reduction of the physiologic nocturnal drop of BP has also been reported in depressed elderly women during 8 weeks of treatment with nortriptyline. This could be explained by sympathetic hyperactivity leading to peripheral vascular dilatation, suggesting that nortriptyline can affect $\mathrm{BP}$ in depressed elderly individuals. ${ }^{80}$

\section{CONCLUSION}

The relationship between depression and BP is a complex issue. Published reports describe higher BP levels, higher incident hypertension, hypotension, and circadian variation abnormalities in depressed patients. Several causative factors have been proposed to explain this association, such as autonomic nervous system dysfunction, and more recently, genetic influences. The clinical relevance of this theme is clear, since depressive symptomatology is associated with poor BP control in hypertensive patients and with the development of complications of hypertension. Finally, extra care must be taken with depressive hypertensive patients to minimize the side effects on BP of antidepressants.

\section{RESUMO}

Scalco AZ, Scalco MZ, Azul JBS, Lotufo Neto F. Hipertensão arterial sistêmica e depressão. Clinics. 2005;60(3): 241-50.

Apesar das altas prevalências de hipertensão arterial sistêmica e de depressão, o estudo da relação entre depres- são e pressão arterial tem recebido pouca atenção da literatura. Nesse artigo são revisados os aspectos epidemiológicos, patofisiológicos, prognósticos e implicações no tratamento, relacionados à associação entre depressão e hipertensão arterial sistêmica. O método utilizado foi consulta ao banco de dados bibliográficos Medline, utilizando-se as 
palavras chave depression, blood pressure, blood pressure variability, physical morbidity, hypertension, mood, stress, hypertension, antidepressive agents e genetics, no período de 1980 a 2004. Encontramos descrições de prevalência aumentada de hipertensão em pacientes deprimidos, prevalência aumentada de depressão em pacientes hipertensos, associação entre sintomatologia depressiva e hipotensão e alteração da variação circadiana da pressão arterial de pacientes deprimidos. Acredita-se que mecanismos envolvendo hiperatividade de sistema nervoso simpático e influências genéticas possam ser a base fisiopa- tológica da relação entre depressão e hipertensão arterial sistêmica. Além disso, a presença de depressão pode piorar o curso da doença hipertensiva, e o uso medicações antidepressivas pode induzir aumento de pressão arterial, diminuição de pressão arterial e hipotensão ortostática, dificultando o manejo de pacientes com hipertensão arterial sistêmica.

\section{UNITERMOS: Depressão. Cardiologia. Hipertensão. Pressão arterial. Antidepressivos.}

\section{REFERENCES}

1. Light KC. Psychosocial precursors of hypertension: Experimental evidence. Circulation. 1987;76(Suppl I):67-76.

2. Grassi G, Esler M. How to assess sympathetic activity in humans. J Hypertension. 1999;17(6):719-34.

3. Adamis D, Ball C. Physical morbidity in elderly psychiatric inpatients: Prevalence and possible relations between the major mental disorders and physical illness. Int J Geriatr Psychiatry. $2000 ; 15(3): 248-53$.

4. Nakagawara M, Witzke W, Matussek N. Hypertension in depression. Psychol Res. 1987;21(1):85-6.

5. Shinagawa M, Otsuda K, Murakami S, Kubo Y, Cornelissen G, Matsubayashi K et al. Seven-day (24-h) ambulatory blood pressure monitoring, self-reported depression and quality of life scores. Blood Press Monit. 2002;7(1):69-76.

6. Hughes JW, Stoney CM. Depressed mood is related to highfrequency heart-rate variability during stressors. Psychosom Med. 2000;62(6):796-803

7. Jonas, BS, Franks, P, Ingram, DD. Are symptoms of anxiety and depression risk factors for hypertension? Longitudinal evidence from the National Health and Nutrition Examination Survey I Epidemiologic Follow-up Study. Arch Fam Med. 1997;6(1):43-9.

8. Jonas BS, Lando JF. Negative affect as a prospective risk factor for hypertension. Psychosom Med. 2000;62(2):188-96.

9. Rabkin J, Charles E, Kass F. Hypertension and DSM-III depression in psychiatric outpatients. Am J Psychiatry. 1983;140(8):1072-4.

10. Everson AS, Kaplan GA, Goldberg DE, Salomen JT. Hypertension incidence is predicted by high levels of hopelessness in Finish men. Hypertension. 2000;34(2):561-7.

11. Pilgrim JA, Stansfeld S, Marmot M. Low blood pressure, low mood? BMJ. 1992;304(6819):75-8.

12. Amsterdam JD, Garcia-Espana F, Fawcett J, Quitkin FM, Reimherr FW, Rosenbaum JF et al. Blood pressure changes during short-term fluoxetine treatment. J Clin Psychopharmacol. 1999;19(1):9-14.

13. Bengtsson C, Edstrom K, Furunes JA, Tibblin G. Prevalence of subjectively experienced symptoms in a population sample of women with special reference to women with arterial hypertension. Scand J Prim Health Care. 1987;5(3):155-62.
14. Pemberton J. Does constitutional hypotension exist? BMJ. 1989;298(6674):660-2.

15. Stroup-Benham CA, Markides KS, Black SA, Goodwin JS. Relationship between low blood pressure and depressive symptomatology in older people. J Am Geriat Soc. 2000;48(3):250-5.

16. Barrett-Connor E, Palinkas LA. Low blood pressure and depression in older men: a population based study. BMJ. 1994;308(6926):4469 .

17. Kario K, Schwartz JE, Davidson KW, Pickering TG. Gender differences in associations of diurnal blood pressure variation, awake physical activity, and sleep quality with negative affect. Hypertension. 2001;38(5):997-1002.

18. Shinagawa M, Otsuka K, Murakami S, Kubo Y, Cornelissen G, Matsubayashi K et al. Seven-day ( $24 \mathrm{~h})$ ambulatory BP monitoring, self-reported depression and quality of life scores Blood Press Monit. 2002;7(1):69-76.

19. Lederbogen F, Gernoth C, Hamann B, Kniest A, Heuser I, Deuschle M. Circadian blood pressure regulation in hospitalized depressed patients and non-depressed comparison subjects. Blood Press Monit. $2003 ; 8(2): 71-6$.

20. Stress M. Blood pressure regulation, cognition, and depression in response to orthostatic challenge in African American children: an initial investigation. Behav Med. 2003,29(1):27-32.

21. Schwartz S, Feller A, Perlmuter LC. Postprandial systolic blood pressure and subsyndromal depression. Exp Aging Res. 2001;27:309-18.

22. Pilgrim JA, Crawford M. Low blood pressure and well being. BMJ. 1993;306(6878):655.

23. Jones-Webb R, Jacobs DR, Flack JM, Liu K. Relationship between depressive symptoms, anxiety, alcohol consumption, and blood pressure: Results form the CARDIA study. Alcohol Clin Exp Res. 1996;20(3):420-7.

24. Townsend MH, Bologna NB, Berbee JG. Heart Rate and blood pressure in panic disorder, major depression, and comorbid panic disorder with major depression. Psychiatry Res. 1998;79(2):18790 . 
25. Goldstein D, Lake C. Plasma norepinephrine and epinephrine levels in essential hypertension. Fed. Proc. 1994;43(1):57-62.

26. Rahn KH, Barenbrock M, Hausberg M. The sympathetic nervous system in the pathogenesis of hypertension. J Hypertension. 1999;17(Suppl 3):11-4.

27. Devilliers AS, Russell VA, Carsters ME, Aalbers C, Gagiano CA, Chalton DO, et al. Noradrenergic function and hypothalamicpituitary-adrenal axis activity in primary major depressive disorder. Psychiatry Res. 1987;22(2):127-39.

28. Lake CR, Pickar D, Zeigler MG, Lipper S, Slater S, Murphy DL. High plasma norepinephrine levels in patients with major affective disorder. Am J Psychiatry. 1982;139(10):1315-8.

29. Roy A, Pickar D, Linnoila M, Potter WZ. Plasma norepinephrine levels in affective disorders. Relationship to melancholia. Arch Gen Psychiatry. 1985;42(12):1181-5.

30. Cooper SJ, Kelly JG, King DJ. Adrenergic receptors in depression. Effects of electroconvulsive therapy. Br J Psychiatry. 1985;147:239.

31. Veith RC, Lewis N, Linares O, Barnes RF, Raskind MA, Villacres EC, et al. Sympathetic nervous system activity: Basal and desipramine-induced alterations in plasma norepinephrine kinetics. Arch Gen Psychiatry. 1994;51(5):411-22.

32. Maes M, Meltzer HY, Suy E, Minner B, Calabrese J, Cosyns P. Sleep disorders and anxiety as symptom profiles of sympathoadrenal system hyperactivity in major depression. J Affect Disord. 1993;27(3):197-207.

33. Lechin F, Van Der Dijs B, Orozco B, Lechin ME, Baéz S, Lechin $\mathrm{AE}$ et al. Plasma neurotransmitters, blood pressure, and heart rate during supine-resting, orthostasis, and moderate exercise conditions in major depressed patients. Biol Psychiatry. 1995;38(3):166-73.

34. Bruno RL, Myers ST, Glassman AH. A correlational study of cardiovascular autonomic functioning and unipolar depression. Biol Psychiatry. 1983;18(2):227-35

35. Carney RM, Saunders RD, Freedland KE, Stein P, Rich MW, Jaffe AS. Association of depression with reduced heart rate variability in coronary artery disease. Am J Cardiol. 1995;76(8):562-4.

36. Guinjoan SM, Bernabó JL, Cardinalli DP. Cardiovascular tests of autonomic function and sympathetic skin responses in patients with major depression. J Neurol Neurosurg Psychiatry. 1995;58(3):299-302.

37. Carney RM, Blumenthal JA, Stein PK, Watkins L, Catellier D, Berkman LF, et al. Depression, heart rate variability, and acute myocardial infarction. Circulation. 2001;104(17): 2024-8.

38. Krittayaphong R, Cascio WE, Light KC, Sheffield D, Golden RN, Finkel JB, et al. Heart rate variability in patients with coronary artery disease: differences in patients with higher and lower depression scores. Psychosom Med. 1997;59(3):231-5.

39. Yeragani VK, Rao KA, Pohl RB, Balon R, Srinivasan K. Diminished chaos of heart rate time series in patients with major depression. Biol Psychiatry. 2002;51(9):733-44.

40. Carney RM, Freedland KE, Stein PK, Skala JA, Hoffman P, Jaffe AS. Change in heart rate and heart rate variability during treatment for depression in patients with coronary artery disease. Psychosom Med. 2000;62(5):639-47.
41. Dalack GW, Roose SP. Perspectives on the relationship between cardiovascular disease and affective disorder. J Clin Psychiatry. 1990;51(Suppl 7):4-9.

42. Balogh S, Fitzpatrick DF, Hendricks SE, Paige SR. Increases in heart rate variability with successful treatment in patients with major depressive disorder. Psychopharmacol Bull. 1993;29(2):2016.

43. Khaykin Y, Dorian P, Baker B, Shapiro C, Sandor P, Mironov D, et al. Autonomic correlates of antidepressant treatment using heartrate variability analysis. Can J Psychiatry. 1998;43(2):183-6.

44. Tulen JHM, Bruijn JA, De Man KJ, Pepplinkhuizen L, Van Den Meiracker AH, et al. Cardiovascular variability in major depressive disorder and effects of imipramine or mirtazapine (Org 3770). J Clin Psychopharmacol. 1996;16(2):135-45.

45. Siever LJ, Davis KL. Overview: toward a dysregulation hypothesis of depression. Am J Psychiatry. 1985;142(9):1017-31.

46. Sloan RP, Shapiro A, Baggiela E, Myers M, Gorman JM. Cardiac autonomic control buffers blood pressure variability response to challenge: A psychophysiologic model of coronary artery disease. Psychossom Med. 1999;61(1):58-68.

47. Broadley AJM, Korszun A, Jones CJH, Frenneaux MP. Arterial endothelial function is impaired in treated depression. Heart. $2002 ; 88(5): 521-4$

48. Rozanski A, Blumenthal JA, Kaplan J. Impact of psychological factors on the pathogenesis of cardiovascular disease and implications for therapy. Circulation. 1999;99(16):2192-217.

49. James AS. Psychosocial precursors of hypertension: A review of the epidemiologic evidence. Circulation. 1987;76(Suppl I):60-5.

50. Buck CW, Donner AP. Blood pressure control in hypertensives - a model for the study of life events. J Chron Dis. 1984;37(4):24753.

51. Grassi G, Turri C, Vailati S, Dell'Oro R, Mancia G. Muscle and skin sympathetic nerve traffic during the "white-coat" effect. Circulation. 1999;100(3):222-5.

52. Waked EG, Jutai JW. Baseline and reactivity measures of blood pressure and negative affect in borderline hypertension. Physiol Behav. 1990;47(2):265-71

53. Chesney MA, Agras S, Benson H, Blumenthal JA, Engel BT, Foreyt JP, et al. Task force 5: Nonpharmacologic approaches to the treatment of hypertension. Circulation. 1987;76(Suppl I):104-9.

54. Southam MA, Agras S, Taylor B, Kraemer HC. Relaxation Training. Blood pressure lowering during the working day. Arch Gen Psychiatry. 1982;39(6):715-7.

55. Grewen KM, Girdler SS, Hinderliter A, Light K. Depressive symptoms are related to higher ambulatory blood pressure in people with a family history of hypertension. Psychosom Med. 2004;66(1):9-16.

56. Lafer B, Vallada Filho H. Genética e fisiopatoloia dos transtornos depressivos. Rev Bras Psiquiatria. 1999;21:S12-S17.

57. Lawler KA, Kline K, Seabrook E, Krishnamoorthy J, Anderson SF, Wilcox ZC, et al. Family history of hypertension: a psychophysiological analysis. Int $\mathrm{J}$ Psychophysiol. 1998;28(2):207-22. 
58. Edwards E, King JA, Fray J. Hypertension and insulin resistant models have divergent propensities to learned helpless behavior in rodents. Am J Hypertension. 2000;13(6 Pt 1):659-65.

59. Martin P, Massol J, Scalbert E, Puech AJ. Involvement of angiotensin-converting enzyme inhibition in reversal of helpless behavior evoked by perindopril in rats. Eur $\mathrm{J}$ Pharmacol. 1990;187(2):165-70.

60. McCaffery JM, Niaura R, Todaro JF, Swan GE, Carmelli D. Depressive symptoms and metabolic risk in adult male twins enrolled in the national heart, lung, and blood institute twin study. Psychosom Med. 2003;65(3):490-7.

61. Cervilla J, Prince M, Joels S, Russ C, Lovestone S. Genes related to vascular disease (APOE, VLDL-R, DCP-1) and other vascular factors in late-life depression. Am J Geriatr Psychiatry. 2004;12(2):202-10.

62. Simonsick E, Wallace R, Blazer D, Berkman L. Depressive symptomatology and hypertension-associated morbidity and mortality in older adults. Psychosom Med. 1995;57(5):427-35.

63. Wassertheil-Smoller S, Applegate WB, Kenneth B, Chee Jen C, Barry D, Grimm RJ et al. Change in depression as a precursor of cardiovascular events. SHEP Cooperative Research Group. Arch Intern Med. 1996;156(5):553-61.

64. Oshira T, Iso H, Satoh S, Sankai T, Tanigawa T, Ogawa Y, et al. Prospective study of depressive symptoms and risk of stroke among japanese. Stroke. 2001;32(4):903-7.

65. Abramson, J, Berger, A, Krumholz, HM, Vaccarino VA. Depression and risk of heart failure among older persons with isolated systolic hypertension. Arch Internal Med. 2001;161(14):1725-30.

66. Penninx B, Beekman A, Honig A, Deeg D, Schoevers R, van Eijk $\mathrm{J}$, et al. Depression and cardiac mortality: results from a communitybased longitudinal study. Arch Gen Psychiatry. 2001;58(3):2217.

67. Musselman DL, Tomer A, Manatunga AK, Knight BT, Porter MR, Kasey S, et al. Exaggerated platelet reactivity in major depression. Am J Psychiatry. 1996;153(10):1313-7.

68. Delisi JSM, Konopka LM, Russel K, O'Connor FL, Cooper R, Crayton JW. Platelet cytosolic calcium hyperresponsivity to serotonin in patients with hypertension and depressive symptoms. Biological Psychiatry. 1999;45:1035-41.

69. Greenwald BS, Kramer-Ginsberg E, Krishnan KR, Hu J, Ashtari $\mathrm{M}, \mathrm{Wu} \mathrm{H}$, et al. A controlled study of MRI signal hyperintensities in older depressed patients with and without hypertension. J Am Geriatr Soc. 2001;49(9):1218-25.
70. Feighner JP. Cardiovascular safety in depressed patients: focus on venlafaxine. J Clin Psychiatry. 1995;153(Suppl 3):77-86.

71. Thase ME. Effects of Venlafaxine on blood pressure: a metaanalysis of original data from 3744 depressed patients. J Clin Psychiatry. 1998;59(10):502-8

72. Esler MD, Wallin G, Dorward PK, Eisenhofer G, Westerman R, Meredith I, et al. Effects of desipramine on sympathetic nerve firing and norepinephrine spillover to plasma in humans. Am J Physiol. 1991;260(4 Pt 2):R817-23

73. Grubb BJ, Samoil DJ, Kosinski D, Wolfe DJ, Lortin M, Madu E. Fluoxetine hydrochloride for the treatment of severe refractory orthostatic hypotension. Am J Med. 1994;97:366-8.

74. Grubb BJ, Samoil DJ, Kosinski D, Kip K, Brewster P. Use of sertraline hydrochloride in the treatment of refractory neurocardiogenic syncope in children and adolescents. J Am Coll Cardiol. 1994;24(2):490-4

75. Grubb BP, Wolfe DA, Samoil DJ, Temesy-Armos P, Hahn H, Elliot L. Usefulness of fluoxetine hydrochloride for the prevention of resistant upright tilt induced syncope. Pacing Clin Electrophysiol. 1993;16(3 Pt 1):458-64.

76. Grubb BP, Samoil DJ, Kosinski D, Temesy-Armos P, Akpunonu B Use of serotonin reuptake inhibitors for the treatment of recurrent syncope due to carotid sinus hypersensitivity unresponsive to dual chamber cardiac pacing. Pacing Clin Electrophysiol. 1994;17(8):1434-6.

77. Scalco MZ, Almeida OP, Hachul DT, Castel S, Serro-Azul J, Wajngarten M. Comparison of risk of orthostatic hypotension in elderly depressed hypertensive women treated with nortriptyline and thiazides versus elderly depressed normotensive women treated with nortriptyline. Am J Cardiol. 2000;85(9):1156-8.

78. Constantino EA, Roose SP, Woodring S. Tricyclic-induced orthostatic hypotension. Pharmacopsychiat. 1993;26(4):125-7.

79. Schwartz S, Feller A, Perlmuter LC Postprandial systolic blood pressure and subsyndromal depression. Exp Aging Res. 2001;27(4):309-18

80. Scalco MZ, Serro-Azul J, Giorgi D, Almeida OP, Wajngarten M. Effect of nortriptyline on the day-night systolic blood pressure difference in hypertensive and normotensive elderly depressed women. Am J Cardiol. 2003;91(10):1279-81. 